\title{
Chất lượng giáo dục và đào tạo tác động đến mức độ hài lòng của học sinh
}

\section{The quality of education impacts on student satisfaction}

\author{
Nguyễn Phương Thúy ${ }^{1}$, Nguyễn Văn Phương ${ }^{1 *}$ \\ ${ }^{1}$ Trường Đại học Quốc tế, Đại học Quốc gia Thành phố Hồ Chí Minh, Việt Nam \\ *Tác giả liên hệ, Email: nvphuong@hcmiu.edu.vn
}

\section{THÔNG TIN}

DOI: $10.46223 /$ HCMCOUJS. soci.vi.15.1.425.2020

Ngày nhận: 09/01/2020

Ngày nhận lại: 22/01/2020

Duyệt đăng: 03/02/2020

\section{Tù khóa:}

chất lượng giáo dục, cơ sở vật chất, hài lòng của học sinh, kỹ năng sống, quản lý đào tạo

\section{Keywords:}

quality of education, school facilities, student satisfaction, life skills, training management

\section{TÓM TĂT}

Nghiên cứu nhằm xác định sự hài lòng của học sinh đối với chất lượng giáo dục và đào tạo với bốn thành phần: chương trình giảng dạy, khả năng giáo dục kỹ năng sống, cơ sở vật chất và cách quản lý đào tạo của Nhà trường. Nghiên cứu được thực hiện trên cơ sở khảo sát 372 học sinh trung học phổ thông trên địa bàn huyện Ba Tri, tỉnh Bến Tre. Kết quả phân tích hồi quy cho thấy cách tổ chức quản lý đào tạo của Nhà trường và cơ sở vật chất có tác động tích cực đến sự hài lòng của học sinh. Ngoài ra, chương trình giảng dạy và khả năng giáo dục kỹ năng sống cho học sinh có tác động chưa thật sự tích cực đến sự hài lòng của học sinh. Nhìn chung, kết quả giúp các nhà quản lý nắm bắt được tâm tư, nguyện vọng của học sinh, từ đó xây dựng cho đơn vị mình một chương trình giảng dạy phù hợp hướng đến mục tiêu chất lượng giáo dục và đào tạo, nâng cao uy tín cho Nhà trường.

\begin{abstract}
This paper aims to identify the level of student satisfaction with the quality of education in terms of four components: school curriculum, training courses in life skills, school facilities, and school management of educational programs. This study was based on a survey of 372 high school students from Ba Tri district in Ben Tre province. The estimated results from the regression analysis show that training management of schools and school facilities have a positive impact on student satisfaction. In addition, curriculum and training courses in life skills hardly have a positive influence on student satisfaction. In general, the findings enable school management to understand students' mindsets and aspirations; thereby, they can make appropriate curriculum reform to improve the quality of education and enhance school prestige.
\end{abstract}




\section{Giới thiệu}

Hiện nay, chất lượng giáo dục và đào tạo cấp trung học phổ thông (THPT) mang tính chất quan trọng, nó quyết định chất lượng và kết quả đạt được để học sinh sau khi tốt nghiệp THPT có được năng lực phù hợp mà chọn trường Đại học, Cao đẳng cho bản thân. Vì thế việc đánh giá chất lượng giáo dục và đào tạo tại trường THPT công lập đóng vai trò quan trọng trong quá trình phát triển của Nhà trường. Các yếu tố về chất lượng dịch vụ giáo dục như Thư viện, trang thiết bị phục vụ thực hành, cơ sở vật chất, chương trình đào tạo, phương pháp giảng dạy, các dịch vụ hành chính phục vụ học sinh của Nhà trường có ảnh hưởng lớn hài lòng của học sinh và phụ huynh.

Riêng đối với cơ sở vật chất trường học, bao gồm tất cả các loại kiến trúc sử dụng cho mục đích học thuật và phi học thuật, thiết bị, phòng học, nội thất, tài liệu giảng dạy, thiết bị hỗ trợ nghe nhìn, nhà vệ sinh, công nghệ thông tin, thư viện, tài liệu phòng thí nghiệm và các tài liệu khác, đóng vai trò then chốt đối với vận hành trơn tru quá trình đào tạo (Afework \& Asfaw, 2014). Bên cạnh đó đội ngũ giáo viên là những người trực tiếp giảng dạy, truyền đạt kiến thức cho học sinh trong các trường học. Nhiều giáo viên luôn có động lực để tự rèn luyện nâng cao trình độ chuyên môn và chất lượng truyền đạt kiến thức. Tuy nhiên, một số giáo viên khác thì hiếm khi có những nỗ lực phấn đâuu nâng cao chuyên môn của họ (Shawer, 2010). Chính vì lẽ đó, xã hội không những đang quan tâm nhiều đến chất lượng và cơ hội phát triển đội ngũ giáo viên mà còn quan tâm đến năng lực truyền đạt kiến thức của giáo viên mặc dù họ sử dụng cùng loại sách giáo khoa giảng dạy chung. Việc phát triển chuyên môn của giáo viên có ảnh hưởng đến việc thực hiện chương trình giảng dạy và việc học tập của học sinh (Craig, 2003). Một số nghiên cứu khác đã khai thác cụ thể hơn những vấn đề mà xã hội quan tâm: một là triển khai sách giáo khoa mới ảnh hưởng như thế nào đến đội ngũ giáo viên và học sinh (Randolph, Duffy, \& Mattingly, 2007; Shawer, Gilmore, \& Banks-Joseph, 2008); hai là các phương pháp giảng dạy có ảnh hưởng rất nhiều đến sự phát triển đội ngũ giáo viên (Roehrig, Kruse, \& Kern, 2007; Shawer, 2017); ba là phát triển đội ngũ giáo viên có chuyên môn có ảnh hưởng đến việc triển khai áp dụng sách giáo khoa và kết quả học tập của học sinh (Lee, Maerten-Rivera, Penfield, Leroy, \& Secada, 2008). Tóm lại, phát triển đội ngũ giáo viên có chuyên môn đóng vai trò rất quan trọng trong việc nâng cao chất lượng hệ thống giáo dục phổ thông của bất kỳ quốc gia nào trên thế giới.

Ở Việt Nam, việc đánh giá chất lượng giáo dục và đào tạo ở các trường THPT dựa trên hệ thống các tiêu chuẩn, tiêu chí và chỉ số đánh giá, kiểm định chất lượng giáo dục. Nó bao gồm quy trình đánh giá trong (do các trường tự đánh giá) và đánh giá ngoài (do đoàn kiểm tra đánh giá), quy trình này tốn khá nhiều thời gian và gặp không ít khó khăn về hồ sơ, tài liệu minh chứng. Tuy nhiên, việc đánh giá chất lượng giáo dục và đào tạo chưa có sự tham gia tích cực của các bên có liên quan như học sinh và phụ huynh và lấy ý kiến phản biện từ các nhà nghiên cứu liên quan. Vì vậy, việc đánh giá chất lượng giáo dục và đào tạo trong thời gian qua ở Việt Nam chưa hoàn toàn toàn diện. Ở một số quốc gia khác đã áp dụng đánh giá chất lượng giáo dục và đào tạo thông qua các hồ sơ lưu trữ hành chính, sự hài lòng của học sinh, phụ huynh, và cán bộ, giáo viên, nhân viên Nhà trường. Mặc dù, phương pháp đánh giá này được áp dụng rộng rãi nhưng trong thực tế việc làm này chưa đạt được tính thống nhất vì nó phụ thuộc vào cá nhân được đánh giá và các mặt liên quan trong suốt quá trình đánh giá. Ngoài ra, việc đánh giá còn phụ thuộc, khác nhau ở từng quốc gia hay từng khu vực (Song \& Meier, 2018).

Do đó, việc nghiên cứu vai trò của chất lượng giáo dục và đào tạo vẫn có những khoảng trống nhất định tại Việt Nam. Để lấp đầy các khoảng trống đó, bài nghiên cứu này tiến hành 
khảo sát thực tế học sinh tại các trường THPT trên địa bàn huyện Ba Tri, tỉnh Bến Tre để xem xét sự tác động của chương trình giảng dạy, khả năng giáo dục kỹ năng sống cho học sinh, cơ sở vật chất trường học và chất lượng chuyên môn của giáo viên đến sự hài lòng của học sinh về chất lượng giáo dục và đào tạo của Nhà trường. Từ kết quả khảo sát thực tiê̂n, nghiên cứu này đề ra một số hàm ý quản trị để nâng cao sự hài lòng của học sinh đối với chất lượng giáo dục và đào tạo của Nhà trường.

\section{Cơ sở lý thuyết}

Sự hài lòng của công dân đối với các dịch vụ công là những cảm nhận về chất lượng và sự thỏa mãn, hài lòng khi sử dụng dịch vụ (Song \& Meier, 2018). Sự hài lòng thể hiện về hiệu quả hoạt động thấp hay cao. Đôi khi sự hài lòng được gọi là mô hình thể chế, giả định rằng các tổ chức công hoạt động tốt có khả năng tạo ra sự thỏa mãn cao, trong khi các tổ chức hoạt động kém sẽ thúc đẩy sự không hài lòng (Newton \& Norris, 2019). Sự bất cân xứng của thông tin trở thành nguyên nhân gây nên sự không hài lòng mặc dù các tổ chức hoạt động có kết quả tốt (Kelly, 2002).

Theo quan điểm trên, các nhà hoạch định và nghiên cứu chính sách giáo dục đã tập trung nỗ lực cải cách chính sách hướng đến nhu cầu công khai dữ liệu hiệu quả của trường để thông báo chính xác hơn về nhận thức của các bên có liên quan đối với chất lượng trường học (Chingos, 2012). Theo một số nghiên cứu trước, mô hình đánh giá sự hài lòng về hiệu quả dựa trên nhiều chính sách giáo dục đang vận hành và trải qua nhiều năm, các nghiên cứu về sự hài lòng của người tiêu dùng và tiếp thị sử dụng lý thuyết xác nhận kỳ vọng, bao gồm các kỳ vọng là thành phần chính cho sự hài lòng, kỳ vọng được xem là ước mong hay mong đợi của con người (Anderson, 1973; Morgeson, 2013; Oliver, 1980; Riccucci, Van Ryzin, \& Lavena, 2014). Nó bắt nguồn từ nhu cầu cá nhân, kinh nghiệm trước đó và thông tin bên ngoài như quảng cáo, thông tin truyền miệng từ bạn bè, gia đình và đồng nghiệp. Các cá nhân có thể tạo ra một tiêu chuẩn về cái mà người ta muốn nhận xét và so sánh (Oliver, 1980). Tiêu chuẩn này được sử dụng để đánh giá quá trình trải nghiệm với hàng hóa hoặc dịch vụ.

Khi các trải nghiệm không đáp ứng được kỳ vọng của một người khác dẫn đến sự không hài lòng trong khi cá nhân báo cáo mức độ hài lòng cao hơn để trải nghiệm vượt quá mong đợi. Như tài liệu này cho thấy, sự hài lòng là sự tương tác phức tạp giữa những kỳ vọng của một người khác về một hàng hóa hoặc dịch vụ cụ thể và một kinh nghiệm của một người khác với hàng hóa hoặc dịch vụ (Oliver, 1980) và trong lĩnh vực quản lý và quản lý công đã áp dụng lý thuyết này vào sự hài lòng của người dân đối với các dịch vụ của chính phủ (Morgeson, 2013; Roch \& Poister, 2006; Van Ryzin, Muzzio, Immerwahr, Gulick, \& Martinez, 2004).

\subsection{Chưong trình giảng dạy}

Đổi mới chương trình giảng dạy đã trở thành một quá trình nâng cao vai trò cho giáo viên và học sinh, một thay đổi trong suy nghĩ và thực hành trong khi vai trò của giáo viên là thích nghi và bổ sung chương trình giảng dạy bên ngoài đến việc tạo ra chương trình giảng dạy (Shawer et al., 2008). Điều này đồng nghĩa với các xu hướng hiện nay đòi hỏi sự phát triển chuyên môn của giáo viên thực hiện thông qua suy nghĩ và học hỏi (Craig, 2007; Knight, Tait, \& Yorke, 2006). Giáo viên giảng dạy và phát triển chuyên môn là hai yếu tố phụ thuộc lẫn nhau là nền tảng cho Nhà trường đạt hiệu quả về giảng dạy, học tập và thực hiện chương trình giảng dạy (Latham \& Vogt, 2007; Shawer et al., 2008). Nhìn chung các nghiên cứu trước đây đã cho thấy chương trình giảng dạy có ảnh hưởng quan trọng đến khả năng phát triển của học sinh và từ đó làm gia tăng mức độ hài lòng của học sinh. 


\subsection{Cơ sở vật chất}

Theo (Akinsolu, 2004) cơ sở vật chất là nguồn lực vật chất tạo điều kiện cho việc giảng dạy và học tập hiệu quả chúng bao gồm các lớp học, phòng thí nghiệm, phòng lưu trữ, hội trường, thư viện, thiết bị, vật tư tiêu hao, điện, nước, thiết bị hỗ trợ nghe nhìn, bàn, ghế, sân chơi. Rõ ràng cơ sở vật chất đóng vai trò quan trọng đến việc nâng cao chất lượng đào tạo và giúp cho học sinh cảm thấy tiện nghi khi đến trường và thoải mái khi lên lớp.

\subsection{Cách tổ chức quản lý đào tạo của Nhà trường}

Cách tổ chức quản lý đào tạo của Nhà trường thông qua việc tổ chức lớp học, phân công giáo viên chủ nhiệm và giáo viên đứng lớp. Giáo viên là người truyền đạt, truyền tải chương trình giảng dạy, cung cấp kiến thức chuyên môn cho học sinh, là người trực tiếp phát triển kỹ năng sư phạm cũng như các hoạt động ngoại khóa của mình để phục vụ cho học sinh. Giáo viên là thành phần quan trọng trong cơ sở giáo dục vì chất lượng giáo dục và đào tạo của Nhà trường được quyết định bởi trình độ chuyên môn, năng lực sư phạm, kỹ năng giảng dạy, quản lý, điều hành, kỹ năng xử lý tình huống, tư vấn, giúp đỡ, động viên, truyền đạt, quan tâm và chia sẻ với học sinh để làm sao học sinh đạt kết quả tốt nhất (Shawer, 2010). Như vậy, giáo viên có kỹ năng sư phạm tốt thì sẽ giúp học viên nắm bắt kiến thức nhanh và hài lòng với việc học. Hơn nữa, nếu Nhà trường triển khai công tác quản lý và điều phối lớp học tốt sẽ tăng cường chất lượng đào tạo và làm cho học viên yêu quý Nhà trường hơn.

\subsection{Phát triển chuyên môn giáo viên}

Phát triển chuyên môn giáo viên là sự đổi mới, cải tiến về chuyên môn liên tục và các kỹ năng trong suốt quá trình giảng dạy. Đổi mới, cải tiến chuyên môn là một phần của giáo dục thường xuyên, nó bao gồm tất cả các hình thức học tập chuyên nghiệp được thực hiện bởi các giáo viên có nhiều kinh nghiệm về chương trình đào tạo (Craig, 2003). Để phát triển chuyên môn giáo viên là một quá trình mà giáo viên tiếp tục mở rộng và nâng cao năng lực chuyên môn của mình thông qua chương trình giảng dạy ở các khối lớp, một quá trình mà giáo viên nâng cao chương trình giảng dạy chính thức thông qua việc nâng cao các tài liệu giảng dạy, bổ sung chương trình giảng dạy, viết giáo trình, lựa chọn sắp xếp nội dung giảng dạy hoặc tạo ra một chương trình giảng dạy mới, hấp dẫn, lôi cuốn ở các cấp học và đánh giá người học trên cơ sở đánh giá nhu cầu cụ thể người học (Shawer, 2010).

\subsection{Mối quan hệ giữa chất luọng giáo dục và sụ hài lòng}

Giese và Cote (2000) cho rằng sự hài lòng của khách hàng bị tác động bởi nhiều yếu tố như: chất lượng sản phẩm, chất lượng dịch vụ, giá cả, yếu tố tình huống, yếu tố cá nhân. Kotler và Armstrong (2008) cho rằng hài lòng là hàm của sự khác biệt giữa kết quả nhận được và kỳ vọng. Parasuraman, Berry, và Zeithaml (1993) cho rằng giữa chất lượng dịch vụ và sự hài lòng khách hàng tồn tại một số khác biệt, điểm khác biệt cơ bản là vấn đề "nhân quả".

Trong giáo dục công, mối quan hệ giữa sự hài lòng và chất lượng dịch vụ của các bên có liên quan cũng được nhiều nghiên cứu khẳng định. Chua (2004) đã nghiên cứu đánh giá chất lượng đào tạo đại học theo nhiều quan điểm, góc nhìn khác nhau: sinh viên, phụ huynh, giảng viên và người sử dụng lao động. Kết quả cho thấy, trong hầu hết các thành phần của mô hình SERVQUAL (đồng cảm, năng lực đáp ứng, tin cậy, phương tiện hữu hình, năng lực phục vụ), sinh viên, phụ huynh và người sử dụng lao động đều kỳ vọng cao hơn những gì họ nhận được. 
Nhìn chung qua lược khảo các nghiên cứu trước đây cho thấy những chính sách cải cách giáo dục thông qua chương trình đào tạo, cách tổ chức quản lý đào tạo, chất lượng đội ngũ thầy cô giáo, cơ sở vật chất, phát triển về mặt chuyên môn của giáo viên, và những hoạt động cung cấp thêm kỹ năng sống cho học sinh đóng vai trò quan trọng đối với việc nâng cao chất lượng đào tạo và gia tăng mức độ hài lòng của học sinh. Tuy nhiên, khi nghiên cứu về sự hài lòng thì phần lớn các nghiên cứu tập trung chủ yếu vào các chất lượng các dịch vụ thương mại. Có rất ít nghiên cứu liên quan mối tương quan giữa chất lượng đào tạo và sự hài lòng của học sinh ở những vùng xa trung tâm các thành phố lớn của các nước đang phát triển. Chính vì vậy nghiên cứu này muốn xem xét mối quan hệ chất lượng dịch vụ đào tạo trong nhiều góc độ khác nhau có liên hệ như thế nào đối với các bên liên quan chủ yếu tại huyện Ba Tri, tỉnh Bến Tre. Thực tế cho thấy chất lượng dịch vụ và sự hài lòng của các bên liên quan có mối quan hệ chặt chẽ. Chất lượng dịch vụ là yếu tố quan trọng tác động đến sự hài lòng của các bên. Nếu học sinh và phụ huynh đánh giá càng cao về chất lượng dịch vụ đào tạo thì mức độ hài lòng của họ về vấn đề này càng cao và ngược lại.

Từ những cơ sở lý thuyết có liên quan giúp phát triển các giả thuyết sau:

H1: Chuơng trình học về lý thuyết càng phù hợp thì mức độ hài lòng của học sinh càng cao

H2: Chương trình học hiện tại có định hương về nghề nghiệp cho học sinh càng tốt thì múc độ hài lòng của học sinh càng cao

H3: Nhà trưòng có định hương việc học, lựa chọn phân ban theo năng lục cho học sinh càng tốt thì mức độ hài lòng của học sinh càng cao

H4: Chuoong trình học giúp học sinh đạt được mục tiêu của mình càng cao thì múc độ hài lòng của học sinh càng cao

H5: Chuoong trình học hương dẫn thực hành, khám phá, trải nghiệm thực tế nội dung liên quan đến môn học cho học sinh càng tốt thì mức độ hài lòng của học sinh càng cao.

H6: Nhà trương có giáo dục khả năng làm việc nhóm cho học sinh càng tốt thì mức độ hài lòng của hoc sinh càng cao

H7: Nhà trường có giáo dục ý thức, trách nhiệm với cộng đồng, xã hội cho học sinh càng tốt thì mức độ hài lòng của học sinh càng cao

H8: Nhà truờng có giáo dục lòng yêu thuơng, hiếu thảo đối với ông bà, cha, mẹ và kính trọng thầy cô cho học sinh càng tốt thì mức độ hài lòng của học sinh càng cao

H9: Nhà trường có giáo dục về kỹ năng trình bày ý kiến, diê̂n đạt, thuyết trình truớc đám đông cho học sinh càng tốt thì mức độ hài lòng của học sinh càng cao

H10: Phòng học, phòng chưc năng, thí nghiệm-thục hành của nhà truò̀ng (về diện tích, mức độ kiên cố, ánh sáng, quạt đèn...) càng tốt thì mức độ hài lòng của học sinh càng cao

H11: Thiết bị thưc hành, đồ dùng dạy học phục vụ dạy và học của Nhà truò̀ng càng đầy đủ thì múc độ hài lòng của học sinh càng cao

H12: Chất luợng, tính úng dụng của đồ dùng, thiết bị dạy học của Nhà truờng càng tốt thì múc độ hài lòng của học sinh càng cao

H13: Thu viện của Nhà truòng (sổ sách mươn trả, sách phục vu học tập, số luợng sách...) phục vu công tác dạy và học càng tốt thì múc độ hài lòng của học sinh càng cao 
H14: Sân chơi, bãi tập thể dục thể thao phục vu dạy và học của Nhà trường càng tốt thì múc độ hài lòng của hoc sinh càng cao

H15: Công tác tổ chức dạy học của Nhà trường (cách sắp xếp lịch học, sắp xếp các môn hoc, cách sắp xếp giáo viên chủ nhiệm, giáo viên bộ môn) càng phù hợp thì mức độ hài lòng của hoc sinh càng cao

H16: Phưong pháp giảng dạy của giáo viên Nhà truò̀ng (dạy dễ hiểu, khả năng truyền đạt lôi cuốn, hấp dẫn ...) càng tốt thì mức độ hài lòng của học sinh càng cao

H17: Công tác chủ nhiệm của giáo viên lớp (năng lục sư phạm, kỹ năng quản lý, điều hành, kỹ năng xử lý tình huống, tu vấn, giúp đõ̃, động viên, giáo dục giá trị sống...) càng tốt thì múc độ hài lòng của học sinh càng cao

H18: Giáo viên bộ môn (phẩm chất đạo đức, phuoong pháp giảng dạy, trình độ chuyên môn, năng lực su phạm) càng tốt thì múc độ hài lòng của học sinh càng cao

Ghi chú: mức độ hài lòng của học sinh được đo bằng 6 biến phụ thuộc cụ thể là $\mathbf{a}:$ kết quả học tập, b: kết quả hạnh kiểm, c: kết quả đạo đức, d: năng lực tự giải quyết vấn đề, e: kết quả giáo dục thể chất, f: kết quả giáo dục kỹ năng sống. Ví dụ, để diễn đạt cụ thể H1 thông qua 6 biến phụ thuộc này sẽ gồm $\mathrm{H} 1 \mathrm{a}, \mathrm{H} 1 \mathrm{~b}, \mathrm{H} 1 \mathrm{c}, \mathrm{H} 1 \mathrm{~d}, \mathrm{H} 1 \mathrm{e}$ và $\mathrm{H} 1 \mathrm{f}$.

\section{Phương trình hồi quy được sử dụng trong quá trình nghiên cứu}

$$
\begin{aligned}
Y_{1,2,3,4,5,6}= & \beta_{0}+\beta_{1} X_{1}+\beta_{2} X_{2}+\beta_{3} X_{3}+\beta_{4} X_{4} \\
\Leftrightarrow Y_{1,2,3,4,5,6} & =\beta_{0}+\beta_{1} C S+\beta_{2} A S+\beta_{3} S F+\beta_{4} A Q S
\end{aligned}
$$

Trong đó:

$Y_{1,2,3,4,5,6}$ : Sự hài lòng về kết quả học tập (TRS1); Sự hài lòng về kết quả hạnh kiểm (TRS2); Sự hài lòng về kết quả đạo đức (TRS3); Sự hài lòng về tự giải quyết vấn đề trong học tập (TRS4); Sự hài lòng về kết quả giáo dục thể chất (TRS5); Sự hài lòng về kết quả giáo dục kỹ năng sống (TRS6).

$\mathrm{X}_{1}$ : Chương trình giảng dạy của nhà trường $(\mathrm{CS})$

$\mathrm{X}_{2}$ : Khả năng giáo dục kỹ năng sống cho học sinh của nhà trường (AS)

$\mathrm{X}_{3}$ : Cơ sở vật chất của nhà trường $(\mathrm{SF})$

$\mathrm{X}_{4}$ : Cách tổ chức quản lý đào tạo của nhà trường (AQS)

$\beta_{0}$ : không đồi

$\beta_{1 \ldots} \beta_{4}$ : Hệ số hồi quy một phần

\section{Phương pháp nghiên cứu}

\subsection{Dũ liệu}

Dữ liệu nghiên cứu được khảo sát trực tiếp thông qua bảng câu hỏi chi tiết với bảng thang đo được xây dựng thành hai phần, phần thứ nhất được xây dựng theo dạng trả lời câu hỏi Có/không, phần thứ hai thang đo được xây dựng theo thang đo Likert 5 điểm với mức độ tăng dần từ yếu đến tốt: 1 : Yếu; 2: Kém; 3: Trung bình; 4: Khá; và 5: Tốt. 
Ngoài ra, tác giả còn thực hiện phỏng vấn nhóm với 5 giáo viên có thâm niên trên 20 năm giảng dạy và 5 phụ huynh có con đã học xong THPT. Kết quả phỏng vấn giúp phát triển các thang đo có tính chất đặc thù của hệ thống giáo dục hiện hành của Việt Nam là: chương trình giảng dạy của Nhà trường và khả năng giáo dục kỹ năng sống cho học sinh của Nhà trường.

Bộ thang đo được xây dựng dựa trên các cơ sở lý thuyết nghiên cứu trước và tác giả tự phát triển dựa trên kết quả nghiên cứu định tính phỏng vấn chuyên gia và thảo luận nhóm. Quá trình kiểm tra thang đo sơ bộ thông qua 80 quan sát thử. Sau khi điều chỉnh mốt số nội dung trong bảng khảo sát, tác giả đã tiến hành phát phiếu đến 05 trường THPT trong huyện với tổng số phiếu là 400 phiếu. Sau khi thu thập được hoàn toàn dữ liệu tác giả đã nhập dữ liệu và đưa vào chạy phương trình hồi quy đa biến với 372 phiếu hợp lệ.

Sử dụng các kỹ thuật và phương pháp phân tích dữ liệu như: phân tích hồi quy và cuối cùng là kiểm định giả thuyết.

\subsection{Mẫu nghiên cứu}

Nghiên cứu này được khảo sát trực tiếp tại 5 trường THPT trên địa bàn huyện $\mathrm{Ba}$ Tri, tỉnh Bến Tre. Mỗi trường khảo sát 80 phiếu tập trung ở khối 12. Mô hình nghiên cứu có biến quan sát là 24 . Trong đó số biến quan sát độc lập là 18 và số biến phụ thuộc 6 . Số lượng mẫu cần cho nghiên cứu này theo công thức của (Green, 1991) đề xuất số lượng mẫu cần thiết để thực hiện phân tích hồi quy đa biến theo công thức $\mathrm{N}=50+(8 \mathrm{x}$ số biến quan sát độc lập $)$. Cụ thể, trong nghiên cứu này thực hiện 18 biến quan sát độc lập nên số mẫu cần thiết là =194 mẫu quan sát. Thực tế 3 tháng triển khai khảo sát từ tháng 8 đến 10 năm 2019, tổng số phiếu khảo sát phát đi là 400, thu về được 372 phiếu hợp lệ. Còn lại 28 phiếu không hợp lệ do thiếu thông tin. Như vậy, số mẫu hợp lệ đảm bảo thực hiện nghiên cứu phân tích hồi quy bội.

\subsection{Thang do}

Thang đo các biến độc lập được đại diện cho các khái niệm trong nghiên cứu, thang đo được phát triển dựa trên thang đo gốc của nghiên cứu trước (Song \& Meier, 2018) và trên cơ sở thảo luận nhóm. Thang đo trong nghiên cứu là thang đo đa biến, gồm có 18 biến độc lập và 6 biến phụ thuộc. Đặc biệt, trên cơ sở kết quả phỏng vấn chuyên gia (thảo luận nhóm) và căn cứ vào bối cảnh thực tế của nghiên cứu này, tác giả đã phát triển các biến liên quan đến chương trình giảng dạy của Nhà trường và khả năng giáo dục kỹ năng sống cho học sinh của Nhà trường trên cơ sở câu hỏi trả lời có (ghi nhận là 1 ) hoặc không (ghi nhận là 0 ). Các biến quan sát còn lại kế thừa các nghiên cứu trước và được đánh giá trên thang đo Likert Scale từ 1 (không đồng ý) đến 5 (hoàn toàn đồng ý).

\section{Bảng 1}

Thang đo và nguồn gốc thang đo

\begin{tabular}{|c|c|l|c|}
\hline Các nhân tố & $\begin{array}{l}\text { Mã } \\
\text { hóa }\end{array}$ & \multicolumn{1}{|c|}{ Tên biến } & Nguồn \\
\hline \multirow{2}{*}{} & CS1 & $\begin{array}{l}\text { Chương trình học có nặng về lý thuyết hay } \\
\text { không }\end{array}$ & \\
\cline { 2 - 3 } & CS2 & $\begin{array}{l}\text { Chương trình học hiện tại có định hướng về } \\
\text { nghề nghiệp của em hay không }\end{array}$ & \\
\hline
\end{tabular}




\begin{tabular}{|c|c|c|c|}
\hline Các nhân tố & $\begin{array}{l}\text { Mã } \\
\text { hóa }\end{array}$ & Tên biến & Nguồn \\
\hline \multirow{3}{*}{$\begin{array}{l}\text { Chương trình } \\
\text { giảng dạy của } \\
\text { nhà trường }\end{array}$} & CS3 & $\begin{array}{l}\text { Nhà trường có định hướng việc học, lựa chọn } \\
\text { phân ban theo năng lực của các em hay không }\end{array}$ & \multirow{3}{*}{$\begin{array}{l}\text { Tác giả: do } \\
\text { kêt quả } \\
\text { nghiên cứu } \\
\text { định tính } \\
\text { phỏng vấn } \\
\text { chuyền gia } \\
\text { và thảo } \\
\text { luận nhóm }\end{array}$} \\
\hline & CS4 & $\begin{array}{l}\text { Chương trình học có giúp em đạt được mục } \\
\text { tiêu của mình hay không }\end{array}$ & \\
\hline & CS5 & $\begin{array}{l}\text { Chương trình học có hướng dẫn em thực } \\
\text { hành, khám phá, trải nghiệm thực tế nội dung } \\
\text { liên quan đến môn học hay không }\end{array}$ & \\
\hline \multirow{4}{*}{$\begin{array}{l}\text { Khả năng giáo } \\
\text { dục kỹ năng sống } \\
\text { cho học sinh của } \\
\text { nhà trường }\end{array}$} & AS1 & $\begin{array}{l}\text { Nhà trường có giáo dục cho em có khả năng làm } \\
\text { việc nhóm hay không }\end{array}$ & \multirow{4}{*}{$\begin{array}{l}\text { Tác giả: do } \\
\text { kết quả } \\
\text { nghiên cứu } \\
\text { định tính } \\
\text { phỏng vấn } \\
\text { chuyên gia } \\
\text { và thảo } \\
\text { luận nhóm }\end{array}$} \\
\hline & AS2 & $\begin{array}{l}\text { Nhà trường có giáo dục cho em có ý thức, trách } \\
\text { nhiệm với cộng đồng, xã hội hay không }\end{array}$ & \\
\hline & AS3 & $\begin{array}{l}\text { Nhà trường có giáo dục cho em lòng yêu thương } \\
\text { hiếu thảo đối với ông bà, cha, mẹ và kính trọng } \\
\text { thầy cô... hay không }\end{array}$ & \\
\hline & AS4 & $\begin{array}{l}\text { Nhà trường có giáo dục cho em về kỹ năng trình } \\
\text { bày ý kiến, diễn đạt, thuyết trình trước đám đông } \\
\text { hay không }\end{array}$ & \\
\hline \multirow{5}{*}{$\begin{array}{l}\text { Cơ sở vật chất } \\
\text { của nhà trường }\end{array}$} & SF1 & $\begin{array}{l}\text { Em đánh giá thế nào các phòng học, phòng } \\
\text { chức năng, thí nghiệm-thực hành của nhà } \\
\text { trường (về diện tích, mức độ kiên cố, ánh sáng, } \\
\text { quạt đèn...). }\end{array}$ & \multirow[t]{5}{*}{$\begin{array}{l}\text { (Song \& } \\
\text { Meier, } \\
2018)\end{array}$} \\
\hline & $\mathrm{SF} 2$ & $\begin{array}{l}\text { Em đánh giá thế nào thiết bị thực hành, đồ } \\
\text { dùng dạy học phục vụ dạy và học của nhà } \\
\text { trường. }\end{array}$ & \\
\hline & SF3 & $\begin{array}{l}\text { Em đánh giá thề nào về chất lượng, tính ứng } \\
\text { dụng của đồ dùng, thiêt bị dạy học trong nhà } \\
\text { trường. }\end{array}$ & \\
\hline & SF4 & $\begin{array}{l}\text { Em đánh thế nào về thư viện của nhà trường } \\
\text { (sổ sách mượn trả, sách phục vụ học tập, số } \\
\text { lượng sách...) phục vụ công tác dạy và học. }\end{array}$ & \\
\hline & SF5 & $\begin{array}{l}\text { Em đánh giá thế nào về sân chơi, bãi tập thể } \\
\text { dục thể thao phục vụ dạy và học của nhà } \\
\text { trường. }\end{array}$ & \\
\hline
\end{tabular}




\begin{tabular}{|c|c|c|c|}
\hline Các nhân tố & $\begin{array}{l}\text { Mã } \\
\text { hóa }\end{array}$ & Tên biến & Nguồn \\
\hline \multirow{4}{*}{$\begin{array}{l}\text { Cách tổ chức } \\
\text { quản lý đào tạo } \\
\text { của nhà trường }\end{array}$} & AQS1 & $\begin{array}{l}\text { Em đánh giá thế nào về công tác tổ chức dạy } \\
\text { học của nhà trường (cách sắp xếp lị̂ch học, sắp } \\
\text { xếp các môn học, cách sắp xếp giáo viên chủ } \\
\text { nhiệm, giáo viên bộ môn). }\end{array}$ & \multirow{4}{*}{$\begin{array}{l}\text { (Song \& } \\
\text { Meier, } \\
\text { 2018) }\end{array}$} \\
\hline & AQS2 & $\begin{array}{l}\text { Em đánh giá thế nào về phương pháp giảng } \\
\text { dạy của giáo viên nhà trường (dạy dễ hiểu, khả } \\
\text { năng truyền đạt lôi cuốn, hấp dâ̂n...). }\end{array}$ & \\
\hline & AQS3 & $\begin{array}{l}\text { Em đánh giá thế nào về công tác chủ nhiệm của } \\
\text { giáo viên lớp em như thế nào (năng lực sư phạm } \\
\text { kỹ năng quản lý, điều hành, kỹ năng xử lý tình } \\
\text { huống, tư vấn, giúp đỡ, động viên, giáo dục giá } \\
\text { trị sống...). }\end{array}$ & \\
\hline & AQS4 & $\begin{array}{l}\text { Em đánh giá thế nào về giáo viên bộ môn (phẩm } \\
\text { chất đạo đức, phương pháp giảng dạy, trình độ } \\
\text { chuyên môn, năng lực sư phạm). }\end{array}$ & \\
\hline \multirow{6}{*}{$\begin{array}{l}\text { Sự hài lòng của } \\
\text { học sinh }\end{array}$} & TRS1 & $\begin{array}{l}\text { Em hài lòng cũng như đánh giá thế nào về kết } \\
\text { quả học tập của mình qua sự đánh giá của nhà } \\
\text { trường. }\end{array}$ & \multirow{6}{*}{$\begin{array}{l}\text { (Song \& } \\
\text { Meier, } \\
\text { 2018) }\end{array}$} \\
\hline & TRS2 & $\begin{array}{l}\text { Em hài lòng cũng như đánh giá thế nào về kết } \\
\text { quả hạnh kiềm của mình qua sự đánh gia của } \\
\text { nhà trường. }\end{array}$ & \\
\hline & TRS3 & $\begin{array}{l}\text { Em hài lòng cũng như đánh giá thế nào về kết } \\
\text { quả đạo đức của mình qua sự đánh giá của nhà } \\
\text { trường. }\end{array}$ & \\
\hline & TRS4 & $\begin{array}{l}\text { Em hài lòng cũng như đánh giá thế nào về } \\
\text { năng lực tự giải quyết vấn đề trong học tập của } \\
\text { mình. }\end{array}$ & \\
\hline & TRS5 & $\begin{array}{l}\text { Em hài lòng cũng như đánh giá thế nào về kết } \\
\text { quả giáo dục thể chất của mình. }\end{array}$ & \\
\hline & TRS6 & $\begin{array}{l}\text { Em hài lòng cũng như đánh giá thế nào về kết } \\
\text { quả giáo dục kỹ năng sống cho học sinh của } \\
\text { nhà trường. }\end{array}$ & \\
\hline
\end{tabular}

Nguồn: Kết quả phân tích dữ liệu của nhóm nghiên cứu

\section{Kết quả}

\subsection{Phân tích thống kê mô tả}

Trong tổng số 372 người tham gia khảo sát, trong đó tỷ lệ học sinh nữ trả lời câu hỏi nhiều hơn tỷ lệ nam và có tỷ lệ lần lượt là nữ $64.78 \%$ và nam là $35.22 \%$. Bảng 3 thống kê mô tả các biến quan sát gồm 24 biến, trong đó có 9 biến (từ CS1 đến AS4) được khảo sát trả lời bằng câu hỏi "Có" hoặc "Không", 15 biến còn lại khảo sát bằng thang đo Likert 5 điểm với mức độ đánh giá từ 1 đến 5 . Theo số liệu thống kê trên bảng, ở cột trung bình (Mean) từ biến 
SF1 đến TRS6 thì các hệ số đều trên 3 . Điều này thể hiện mặt tích cực về sự hài lòng của học sinh đối với chất lượng giáo dục của Nhà trường. Trong đó, biến quan sát SF2 có hệ số (Mean) = 3.44 nhỏ nhất trong bảng khảo sát nói về nội dung "Em đánh giá thế nào thiết bị thực hành, đồ dùng dạy học phục vụ dạy và học của Nhà trường”. Biến quan sát TRS2 có hệ số (Mean) = 4.74 cao nhất trong tất cả các biến quan sát nói về "Em nhận thấy như thế nào về kết quả hạnh kiểm của mình qua sự đánh giá của Nhà trường."

\section{Bảng 2}

Thống kê mô tả các biến quan sát

\begin{tabular}{|c|c|c|c|c|c|}
\hline Tên biến & Số mẫu & Minimum & Maximu & Mean & Độ lệch chuẩn \\
\hline CS1 & 372 & 0 & 1 & 0.80 & 0.40 \\
\hline CS2 & 372 & 0 & 1 & 0.60 & 0.49 \\
\hline CS3 & 372 & 0 & 1 & 0.85 & 0.36 \\
\hline CS4 & 372 & 0 & 1 & 0.74 & 0.44 \\
\hline CS5 & 372 & 0 & 1 & 0.36 & 0.48 \\
\hline AS1 & 372 & 0 & 1 & 0.83 & 0.38 \\
\hline AS2 & 372 & 0 & 1 & 0.98 & 0.13 \\
\hline AS4 & 372 & 0 & 1 & 0.98 & 0.14 \\
\hline AS5 & 372 & 0 & 1 & 0.75 & 0.43 \\
\hline SF1 & 372 & 1 & 5 & 3.80 & 0.83 \\
\hline SF2 & 372 & 1 & 5 & 3.44 & 0.95 \\
\hline SF3 & 372 & 1 & 5 & 3.46 & 0.89 \\
\hline SF4 & 372 & 1 & 5 & 3.99 & 0.95 \\
\hline SF5 & 372 & 1 & 5 & 3.66 & 1.00 \\
\hline AQS1 & 372 & 1 & 5 & 3.97 & 0.84 \\
\hline AQS2 & 372 & 1 & 5 & 4.22 & 0.73 \\
\hline AQS3 & 372 & 1 & 5 & 4.59 & 0.76 \\
\hline AQS4 & 372 & 1 & 5 & 4.53 & 0.64 \\
\hline TRS1 & 372 & 1 & 5 & 4.15 & 0.72 \\
\hline TRS2 & 372 & 1 & 5 & 4.74 & 0.55 \\
\hline TRS3 & 372 & 1 & 5 & 4.68 & 0.63 \\
\hline TRS4 & 372 & 1 & 5 & 3.84 & 0.69 \\
\hline TRS5 & 372 & 1 & 5 & 3.97 & 0.85 \\
\hline TRS6 & 372 & 1 & 5 & 3.88 & 0.96 \\
\hline
\end{tabular}

Ghi chú: 1: có; 0: không; 1-5: thang đo Likert 5 điểm.

Nguồn: Kết quả phân tích dữ liệu của nhóm nghiên cứu

\subsection{Kiểm tra hiện tựng đa cộng tuyến}

Trong phân tích kinh tế lượng đối với dữ liệu bảng cắt ngang (cross-sectional data) thì thường xảy ra hiện tượng đa cộng tuyến. Trước khi đánh giá kết quả phân tích hồi quy, việc kiểm tra cộng tuyến (collinearity) bằng cách xem xét kết quả ma trận mối tương quan với tất cả biến giải thích (biến độc lập). Cụ thể, kết quả của ma trận tương quan các biến giải thích dao động từ 0.39 đến 0.62 , ngoại trừ hệ số tương quan giữa SF3 và CS4 là 0.71 . Các hệ số tương 
quan đều nhỏ hơn giá trị qui định 0.8 . Vì vậy, các biến giải thích không có quan hệ chặt chẽ với nhau và hiện tượng cộng tuyến không xảy ra. Để kiểm tra khả năng xảy ra hiện tượng đa cộng tuyến trong phương trình hồi quy có thể dẫn đến hệ số ước lượng không chính xác, tác giả cho tiến hành tính hệ số phỏng đại phương sai (Variance Inflation Factor-VIF) đối với các biến giải thích. Cụ thể, kết quả cho ra giá trị VIF dao động từ 1.10 đến 2.69 , thấp hơn giá trị qui định là 10.

\subsection{Thảo luận kết quả}

Bảng 3 trình bày kết quả phân tích hồi quy của 6 phương trình trong đó 6 biến phụ thuộc đại diện cho 6 khía cạnh khác nhau của mức độ hài lòng của học sinh. Kết quả cho thấy mặc dù thực tế chương trình học nặng về lý thuyết nhưng việc tổ chức thi cử và ra đề thi phải bám theo giáo trình giảng dạy theo qui định chính vì vậy nó ảnh hưởng đến kết quả học tập của học sinh. Lý do này có thể được giải thích rõ hơn là hiện nay mục tiêu giáo dục chương trình phổ thông theo hướng tiếp cận tri thức, giảng dạy lý thuyết theo khung quy định thì bên cạnh đó cũng thực hiện chương trình thực hành nên người thầy đóng vai trò trung tâm, truyền thụ tri thức, hướng dẫn đến học sinh giúp học sinh hình thành năng lực. Điều này có tác động tích cực đến kết quả học tập của học sinh. Kết quả này cũng góp phần quan trọng mà các nghiên cứu liên quan trước đây chưa khai thác hết. Kết quả cũng cho thấy tính đặc thù của hệ thống giáo dục tại Việt Nam khi mà xã hội vẫn ngày một lên án than phiền chương trình giáo dục quá nặng nề về lý thuyết nhưng thực tế thì phụ huynh và học sinh đều muốn đạt thành tích cao trong học tập nên dù muốn hay không vẫn phải học và học thêm ngoài giờ để đạt được kết quả cao trong mỗi kỳ thì thi. Nếu không học thì không thể đạt được kết quả tốt.

\section{Bảng 3}

Kết quả phân tích hồi quy

\begin{tabular}{|c|c|c|c|c|c|c|c|}
\hline & $\begin{array}{l}\text { Mô hình } \\
\text { (1) }\end{array}$ & $\begin{array}{l}\text { Mô hình } \\
\text { (2) }\end{array}$ & $\begin{array}{l}\text { Mô hình } \\
\text { (3) }\end{array}$ & $\begin{array}{l}\text { Mô hình } \\
\text { (4) }\end{array}$ & $\begin{array}{l}\text { Mô hình } \\
\text { (5) }\end{array}$ & $\begin{array}{l}\text { Mô hình } \\
\text { (6) }\end{array}$ & \multirow{2}{*}{ Kết luận } \\
\hline & TRS1 & TRS2 & TRS3 & TRS4 & TRS5 & TRS6 & \\
\hline \multirow[t]{2}{*}{ CS1 } & 0.191 ** & -0.005 & -0.001 & -0.054 & -0.148 & -0.103 & \multirow{2}{*}{$\begin{array}{c}\text { Chấp nhận } \\
\text { H1(H1a) }\end{array}$} \\
\hline & $(0.089)$ & $(0.070)$ & $(0.077)$ & $(0.086)$ & $(0.102)$ & $(0.110)$ & \\
\hline \multirow[t]{2}{*}{ CS2 } & 0.106 & $0.119^{*}$ & 0.028 & 0.027 & 0.041 & 0.047 & \multirow{2}{*}{$\begin{array}{l}\text { Chấp nhận } \\
\text { H2(H2b) }\end{array}$} \\
\hline & $(0.083)$ & $(0.066)$ & $(0.072)$ & $(0.081)$ & $(0.096)$ & $(0.103)$ & \\
\hline \multirow[t]{2}{*}{ CS3 } & 0.031 & 0.026 & -0.101 & $0.183^{*}$ & 0.055 & 0.033 & \multirow{2}{*}{$\begin{array}{c}\text { Chấp nhận } \\
\text { H3(H3d) }\end{array}$} \\
\hline & $(0.103)$ & $(0.082)$ & $(0.089)$ & $(0.100)$ & $(0.119)$ & $(0.128)$ & \\
\hline \multirow[t]{2}{*}{ CS4 } & -0.113 & -0.095 & 0.022 & 0.026 & 0.074 & 0.109 & \multirow{2}{*}{$\begin{array}{c}\text { Không chấp } \\
\text { nhận H4 }\end{array}$} \\
\hline & $(0.090)$ & $(0.071)$ & $(0.077)$ & $(0.087)$ & $(0.103)$ & $(0.112)$ & \\
\hline \multirow[t]{2}{*}{ CS5 } & $-0.174 * *$ & 0.012 & -0.055 & -0.033 & -0.111 & 0.064 & \multirow{2}{*}{$\begin{array}{l}\text { Chấp nhận } \\
\text { ngược chiều } \\
\text { H5(H5a) }\end{array}$} \\
\hline & $(0.080)$ & $(0.063)$ & $(0.069)$ & $(0.077)$ & $(0.092)$ & (0.099) & \\
\hline \multirow[t]{2}{*}{ AS1 } & 0.152 & -0.084 & -0.031 & 0.029 & 0.107 & 0.101 & \multirow{2}{*}{$\begin{array}{c}\text { Không chấp } \\
\text { nhận H6 }\end{array}$} \\
\hline & $(0.104)$ & $(0.083)$ & $(0.090)$ & $(0.101)$ & $(0.119)$ & $(0.129)$ & \\
\hline \multirow[t]{2}{*}{ AS2 } & 0.199 & 0.147 & -0.130 & -0.202 & 0.339 & 0.084 & \multirow{2}{*}{$\begin{array}{l}\text { Không chấp } \\
\text { nhận H7 }\end{array}$} \\
\hline & $(0.322)$ & $(0.255)$ & $(0.277)$ & $(0.313)$ & $(0.370)$ & $(0.401)$ & \\
\hline \multirow[t]{2}{*}{$\mathrm{AS} 3$} & 0.026 & -0.206 & $0.560^{* * *}$ & 0.194 & 0.081 & $0.626^{*}$ & \multirow{2}{*}{$\begin{array}{c}\text { Chấp nhận } \\
\text { H8(H8c; } \\
\text { H8f) }\end{array}$} \\
\hline & $(0.292)$ & $(0.231)$ & $(0.251)$ & $(0.283)$ & $(0.335)$ & $(0.363)$ & \\
\hline
\end{tabular}




\begin{tabular}{|c|c|c|c|c|c|c|c|}
\hline & $\begin{array}{l}\text { Mô hình } \\
\text { (1) }\end{array}$ & $\begin{array}{l}\text { Mô hình } \\
\text { (2) }\end{array}$ & $\begin{array}{l}\text { Mô hình } \\
\text { (3) }\end{array}$ & $\begin{array}{c}\text { Mô hình } \\
\text { (4) }\end{array}$ & $\begin{array}{c}\text { Mô hình } \\
\text { (5) }\end{array}$ & $\begin{array}{c}\text { Mô hình } \\
\text { (6) }\end{array}$ & \multirow{2}{*}{ Kết luận } \\
\hline & TRS1 & TRS2 & TRS3 & TRS4 & TRS5 & TRS6 & \\
\hline \multirow[t]{2}{*}{ AS4 } & 0.108 & -0.019 & 0.100 & 0.133 & $0.226^{* *}$ & $0.292 * *$ & \multirow{2}{*}{$\begin{array}{c}\text { Chấp nhận } \\
\text { H9(H9e; } \\
\text { H9f) }\end{array}$} \\
\hline & (0.093) & (0.074) & $(0.080)$ & (0.090) & $(0.107)$ & $(0.115)$ & \\
\hline \multirow[t]{2}{*}{ SF1 } & $0.098 *$ & -0.037 & -0.033 & $0.098 *$ & -0.058 & 0.101 & \multirow{2}{*}{$\begin{array}{c}\text { Chấp nhận } \\
\text { H10(H10a; } \\
\text { H10d) }\end{array}$} \\
\hline & $(0.057)$ & $(0.045)$ & (0.049) & $(0.055)$ & $(0.065)$ & $(0.071)$ & \\
\hline \multirow[t]{2}{*}{ SF2 } & -0.021 & 0.006 & -0.037 & -0.044 & 0.032 & -0.101 & \multirow{2}{*}{$\begin{array}{c}\text { Không chấp } \\
\text { nhận H11 }\end{array}$} \\
\hline & $(0.059)$ & $(0.046)$ & $(0.050)$ & $(0.057)$ & $(0.067)$ & $(0.073)$ & \\
\hline \multirow[t]{2}{*}{ SF3 } & 0.057 & -0.032 & 0.037 & 0.076 & $0.246 * * *$ & $0.171 * *$ & \multirow{2}{*}{$\begin{array}{c}\text { Chấp nhận } \\
\text { H12(H12e; } \\
\text { H12f) }\end{array}$} \\
\hline & $(0.061)$ & $(0.049)$ & $(0.053)$ & $(0.059)$ & $(0.070)$ & $(0.076)$ & \\
\hline \multirow[t]{2}{*}{ SF4 } & 0.029 & 0.035 & -0.023 & 0.032 & -0.040 & 0.008 & \multirow{2}{*}{$\begin{array}{c}\text { Không chấp } \\
\text { nhận H13 }\end{array}$} \\
\hline & $(0.044)$ & $(0.035)$ & $(0.038)$ & $(0.043)$ & $(0.051)$ & $(0.055)$ & \\
\hline \multirow[t]{2}{*}{ SF5 } & 0.040 & 0.043 & $0.072 *$ & -0.031 & $0.102 * *$ & $0.233 * * *$ & \multirow{2}{*}{$\begin{array}{l}\text { Chấp nhận } \\
\text { H14 (H14c; } \\
\text { H14e; H9f) }\end{array}$} \\
\hline & $(0.045)$ & $(0.036)$ & (0.039) & $(0.044)$ & $(0.052)$ & $(0.056)$ & \\
\hline \multirow[t]{2}{*}{ AQS1 } & 0.036 & 0.038 & 0.028 & -0.039 & $-0.110^{*}$ & 0.005 & \multirow{2}{*}{$\begin{array}{l}\text { Chấp nhận } \\
\text { ngược chiều } \\
\text { H15(H15e) }\end{array}$} \\
\hline & $(0.051)$ & $(0.040)$ & $(0.044)$ & (0.049) & $(0.058)$ & $(0.063)$ & \\
\hline \multirow[t]{2}{*}{ AQS2 } & $0.229 * * *$ & 0.060 & $0.097 *$ & $0.248 * * *$ & $0.157 * *$ & $0.157 * *$ & \multirow{2}{*}{$\begin{array}{l}\text { Chấp nhận } \\
\text { H16 (H16a; } \\
\text { H16c; H16d; } \\
\text { H16e; H16f) }\end{array}$} \\
\hline & $(0.063)$ & $(0.050)$ & $(0.054)$ & $(0.061)$ & $(0.072)$ & $(0.078)$ & \\
\hline \multirow[t]{2}{*}{ AQS3 } & -0.046 & 0.089* & 0.038 & -0.016 & 0.051 & -0.088 & \multirow{2}{*}{$\begin{array}{l}\text { Chấp nhận } \\
\text { H17 (H17b) }\end{array}$} \\
\hline & $(0.060)$ & $(0.047)$ & $(0.051)$ & $(0.058)$ & $(0.068)$ & $(0.074)$ & \\
\hline \multirow[t]{2}{*}{ AQS4 } & 0.097 & $0.172 * * *$ & $0.298 * * *$ & 0.084 & 0.117 & 0.142 & \multirow{2}{*}{$\begin{array}{c}\text { Chấp nhận } \\
\text { H18 (H18b; } \\
\text { H18c) }\end{array}$} \\
\hline & $(0.073)$ & $(0.058)$ & $(0.063)$ & $(0.071)$ & $(0.083)$ & $(0.090)$ & \\
\hline \multirow[t]{2}{*}{ gender } & -0.104 & 0.047 & -0.022 & $0.265 * * *$ & 0.042 & -0.076 & \\
\hline & $(0.075)$ & $(0.059)$ & $(0.064)$ & $(0.073)$ & $(0.086)$ & $(0.093)$ & \\
\hline \multirow[t]{2}{*}{ _cons } & $1.562 * * *$ & $3.183^{* * *}$ & $2.205 * * *$ & $1.797 * * *$ & $1.370 * * *$ & 0.396 & \\
\hline & $(0.411)$ & $(0.325)$ & $(0.353)$ & $(0.398)$ & $(0.471)$ & $(0.510)$ & \\
\hline$N$ & 372 & 372 & 372 & 372 & 372 & 372 & \\
\hline$R^{2}$ & 0.229 & 0.173 & 0.243 & 0.197 & 0.257 & 0.327 & \\
\hline
\end{tabular}

Ghi chú: độ lệch chuẩn trong dấu ngoặc. ${ }^{*} \mathrm{p}<.10, * * \mathrm{p}<.05, * * * \mathrm{p}<0.01$

Nguồn: Kết quả phân tích dữ liệu của nhóm nghiên cứu

Kết quả phân tích hồi quy cho thấy chương trình học có định hướng về nghề nghiệp cho học sinh có tác động tích cực đến kết quả hạnh kiểm của học sinh. Hiện nay chương trình khung theo qui định có tích hợp định hướng nghề nghiệp cho học sinh. Trong một học kỳ, mỗi lớp có 9 tiết học hướng nghiệp về nông nghiệp, công nghiệp, nông lâm thủy sản. Hàng năm điều có các trường cao đẳng, đại học về gặp trực tiếp học sinh để tư vấn, giải đáp thắc mắc về việc chọn trường, chọn ngành và chọn nghề. Từ đó giúp các em tự có ý thức trong việc học tập, rèn luyện hạnh kiểm đạo đức để các em đạt được mục tiêu đề ra của mình. Điều này có tác động tích cực đến kết quả hạnh kiểm của học sinh. Những hoạt động hướng nghiệp cho học sinh trong những năm gần đây theo chiều hướng tích cực hơn. Kết quả này cũng tương đồng với nghiên cứu của 
(Snyder, Bolin, \& Zumwalt, 1992). Đổi mới và bổ sung chương trình giảng dạy bên ngoài có vai trò định hướng tốt cho học sinh. Hay nói cách khác, các hoạt động ngoại khóa sẽ giúp cho học sinh có định hướng nghề nghiệp tốt hơn.

Kết quả phân tích hồi quy cho thấy Nhà trường có định hướng việc học, lựa chọn phân ban theo năng lực của học sinh có quan hệ tích cực đến năng lực tự giải quyết vấn đề trong học tập của học sinh. Điều đó cho thấy việc phân ban tự nhiên và xã hội đầu năm 12 đã giúp ích cho định hướng chuẩn bị tốt chọn ngành học sau khi tốt nghiệp THPT. Việc phân ban nhằm mục đích để học sinh tiếp cận năng lực thông qua học tập hay trải nghiệm thực tế. Việc học sinh tự lựa chọn ban phù hợp với khả năng, năng lực thực tế của mình giúp các em giải quyết được vấn đề trong học tập tốt. Điều này có tác động tích cực đến năng lực tự giải quyết vấn đề trong học tập của học sinh. Ngoài ra, việc phân ban cũng giúp cho các giảng viên phát huy hết khả năng chuyên môn của mình giúp cho việc truyền tải nội dung giảng dạy tốt hơn. Kết quả này cũng tương đồng với những nghiên cứu trước đây đã khẳng định (Shawer, Gilmore, \& Banks-Joseph, 2009).

Kết quả phân tích data cho thấy chương trình học có hướng dẫn thực hành, khám phá, trải nghiệm thực tế nội dung liên quan đến môn học có tác động ngược chiều đến kết quả học tập của học sinh. Cụ thể, trong giai đoạn hiện nay các giáo viên có đầu tư, nghiên cứu để chuyển từ dạy học tiếp cận tri thức sang tiếp cận năng lực. Do vậy, các hoạt động trải nghiệm thực tế có được thực hiện trong năm học nhưng chưa nhiều và mới triển khai thí điểm ở môn ngữ văn và lịch sử. Bên cạnh đó, các giáo viên chưa đầu tư triển khai giảng dạy theo hướng này nên kết quả chưa đạt được như kỳ vọng của các bên có liên quan. Kết quả này trái ngược với một số nghiên cứu trước đây (Latham \& Vogt, 2007; Shawer et al., 2008).

Kết quả phân tích hồi quy cho thấy chương trình có giáo dục lòng yêu thương, hiếu thảo đối với ông, bà, cha, mẹ và kính trọng thầy cô có quan hệ tích cực đến kết quả đạo đức và kết quả giáo dục kỹ năng sống của học sinh. Cụ thể Nhà trường có tích hợp giáo dục thái độ, hành vi, cách ứng xử có văn hóa với người khác, giáo dục cho học sinh lòng yêu thương, hiếu thảo đối với ông bà cha mẹ và kính trọng thầy cô, hòa đồng với bạn bè, tập thể thông qua tuyên truyền dưới cờ, qua góc truyền thông, qua giờ sinh hoạt lớp, ngoài giờ lên lớp. Những tình cảm này giúp học sinh nhận thức nhiều hơn về lối sống đạo đức của người con, người cháu đối với ông, bà, cha, mẹ và người học trò đối với thầy cô. Các em biết ngoài giờ học còn biết phụ giúp gia đình một số việc lao động, sản xuất, buôn bán nhỏ. Điều này có tác động tích cực đến việc nâng cao kết quả đạo đức, kỹ năng sống cho học sinh. Kết quả này cũng góp phần quan trọng mà các nghiên cứu liên quan trước đây chưa khai thác hết.

Kết quả phân tích hồi quy cho thấy chương trình có giáo dục về kỹ năng trình bày ý kiến, diễn đạt, thuyết trình có quan hệ tích cực đến kết quả giáo dục thể chất; kết quả giáo dục kỹ năng sống của học sinh. Việc giáo dục kỹ năng trình bày ý kiến, diễn đạt, thuyết trình diễn ra chủ yếu ở môn ngữ văn, lịch sử, địa lí và sinh học. Bên cạnh đó Nhà trường cũng đưa nội dung này vào tiết sinh hoạt dưới cờ bằng hình thức đố vui để học có liên quan đến kiến thức bài giảng với hai mục đích, thứ nhất là rèn luyện độ nhạy bén, nhanh nhẹn của học sinh, thứ hai là rèn cho học sinh có kỹ năng giao tiếp, phát biểu, diễn đạt trước đám đông. Trong các giờ học này học sinh rất thích thú, hăng say và tiếp thu một cách có hiệu quả, học sinh trang bị được cho mình tính tự tin, khả năng diễn đạt, thuyết trình, khả năng làm việc nhóm, khả năng phân 
vai, vận động tốt. Điều này làm tăng kết quả thể chất và kỹ năng sống của học sinh. Đây cũng là khám phá mới trong nghiên cứu này.

Kết quả phân tích cho thấy phòng học, phòng chức năng, thí nghiệm-thực hành của Nhà trường có quan hệ tích cực đến kết quả học tập; khả năng tự giải quyết vấn đề trong học tập của học sinh. Theo chương trình dự án của Bộ Giáo dục hiện nay các trường học được xây dựng theo trường đạt chuẩn quốc gia, theo đó là trang bị các thiết bị, cơ sở vật chất, khá đầy đủ từ phòng học, phòng chức năng, thực hành thí nghiệm, bàn ghế, máy móc, thiết bị. Cụ thể trường THPT Phan Liêm có 21 phòng học, 7 phòng chức năng, 2 phòng tin học, 2 phòng ngoại ngữ, 2 phòng nghe nhìn, 1 phòng thực hành lí, 1 phòng thực hành hóa và 1 phòng thiết bị. Điều kiện cơ sở vật chất đầy đủ giúp học sinh học tập thuận lợi hơn nâng cao kết quả học tập và giải quyết được các vấn đề trong học tập. Kết quả này cũng tương đồng với nghiên cứu trước đây đã khẳng định (Akinsolu, 2004).

Kết quả phân tích data cho thấy chất lượng, tính ứng dụng của đồ dùng dạy học, thiết bị dạy học trong Nhà trường có quan hệ tích cực đến kết quả giáo dục thể chất; kết quả giáo dục kỹ năng sống của học sinh. Các thiết bị dạy học phục vụ môn thể dục, quốc phòng được Nhà trường trang bị khá đầy đủ vào hàng năm như: nệm nhảy cao, bóng chuyền, bóng đá, bóng rỗ, cầu đá, trụ nhảy cao, trụ bóng rỗ và do giáo viên bộ môn tự làm. Ví dụ như dụng cụ hỗ trợ đệm bóng phục vụ khá tốt việc dạy và học, học sinh có điều kiện tiếp cận, thực hành trên những thiết bị học tập, nâng cao rèn luyện sức khỏe, thể chất. Học sinh có sức khỏe, thể lực tốt, tinh thần sống khỏe giúp học sinh tự tin hình thành kỹ năng làm việc nhóm, kỹ năng giao tiếp, thu thập thông tin, Điều này làm tăng kết quả giáo dục thể chất và giáo dục kỹ năng sống của học sinh. Kết quả này cũng tương đồng với nghiên cứu trước đây đã khẳng định (Akinsolu, 2004).

Kết quả phân tích data cho thấy sân chơi, bãi tập thể dục thể thao có quan hệ tích cực đến kết quả giáo dục đạo đức; kết quả giáo dục thể chất; kết quả giáo dục kỹ năng sống. Đầu tư, thiết kế sân chơi, bãi tập thể dục thể thao cho học sinh tạo điều kiện cho giáo viên và học sinh tổ chức các hoạt động dạy và học. Học sinh có sân chơi và điều kiện để vận động, nâng cao thể chất sau những giờ học lý thuyết căng thẳng. Hiện tại ở các trường có thành lập các câu lạc bộ thể thao do giáo viên làm chủ nhiệm câu lạc bộ. Thông qua các hoạt động này học sinh được rèn luyện, phát triển thể chất, nâng cao sức khỏe. Từ đó, tinh thần và thái độ học tập tích cực hơn. Các điều kiện về sân chơi bãi tập giúp cho học sinh hình thành các kỹ năng hợp tác, chia sẻ thu thập thông tin, kỹ năng điều hành, hình thành năng lực điều hành nhóm, tổ chức các hoạt động nhóm hiệu quả biết phân chia công việc. Điều này làm tăng kết quả đạo đức; kết quả giáo dục thể chất và kết quả kỹ năng sống của học sinh (Akinsolu, 2004).

Theo kết quả phân tích hồi quy ta thấy công tác tổ chức dạy học của Nhà trường (cách xếp lịch học, sắp xếp các môn học, cách sắp xếp giáo viên chủ nhiệm, giáo viên bộ môn) có tác động ngược chiều đến kết quả giáo dục thể chất của học sinh. Hiện tại các trường THPT có chung một chương trình giảng dạy lý thuyết cũng như thực hành, Nhà trường luôn quan tâm đến công tác tổ chức giảng dạy như: cách xếp lịch học, sắp xếp các môn học, cách sắp xếp giáo viên chủ nhiệm, giáo viên bộ môn nhưng bên cạnh đó theo phân phối chương trình số tiết học dành cho môn thể dục-quốc phòng chưa nhiều, được thực hiện 3 tiết/tuần cho cả môn thể dục và quốc phòng. Một bộ phận nhỏ giáo viên truyền đạt kiến thức còn cứng nhắc, chưa đa dạng, phong phú, chưa phát huy được hết tác dụng của bộ môn thể dục-quốc phòng nên kết quả chưa 
đạt được như mong muốn của học sinh. Kết quả này trái ngược với một số nghiên cứu trước đây (Latham \& Vogt, 2007; Shawer et al., 2008).

Theo kết quả nghiên cứu cho thấy phương pháp giảng dạy của giáo viên (dạy dễ hiểu, khả năng truyền đạt lôi cuốn, hấp dẫn...) có quan hệ tích cực đến kết quả học tập; kết quả đạo đức; năng lực tự giải quyết vấn đề; kết quả giáo dục thể chất; kết quả giáo dục kỹ năng sống của học sinh. Hiện nay hầu hết giáo viên điều có trình độ đạt chuẩn và trên chuẩn bên cạnh đó giáo dục cũng quan tâm đến việc đưa cán bộ quản lý, giáo viên đi học hỏi kinh nghiệm, bồi dưỡng, nâng chuẩn về năng lực sư phạm, kỹ năng quản lý, điều hành, kỹ năng xử lý tình huống, tư vấn, giúp đỡ, động viên, giáo dục giá trị sống đầy đủ để vận dụng vào việc giảng dạy. Giáo viên là người trực tiếp truyền đạt kiến thức cho học sinh. Người thầy giỏi, có tâm huyết thì chất lượng học tập cũng như các mặt khác cũng được nâng cao. Bên cạnh đó đòi hỏi các giáo viên cần có đầu tư, nghiên cứu để chuyển từ dạy học tiếp cận tri thức sang tiếp cận năng lực. Giáo viên giảng dạy và phát triển chuyên môn là hai yếu tố có sự quan hệ mật thiết làm nền tảng cho các trường học đạt hiệu quả về giảng dạy, học tập và thực hiện chương trình giảng dạy. Điều này có tác động tích cực đến kết học tập; kết quả đạo đức; năng lực tự giải quyết vấn đề; kết quả giáo dục thể chất; kết quả giáo dục kỹ năng sống của học sinh. Kết quả này cũng tương đồng với những nghiên cứu trước đây đã khẳng định (Latham \& Vogt, 2007; Shawer et al., 2008).

Kết quả phân tích data cho ta thấy công tác chủ nhiệm của giáo viên lớp (năng lực sư phạm, kỹ năng quản lý, điều hành, kỹ năng xử lý tình huống, tư vấn, giúp đỡ, động viên, giáo dục giá trị sống...) có quan hệ tích cực đến kết quả hạnh kiểm của học sinh. Giáo viên chủ nhiệm có nhiều kinh nghiệm chủ nhiệm các lớp học sinh yếu, chưa ngoan như mong đợi, giáo viên xã hội chủ nhiệm các lớp ban xã hội và ngược lại, giáo viên có nhiều kinh nghiệm sẽ bồi dưỡng học sinh giỏi tạo chất lượng mũi nhọn cho Nhà trường và hỗ trợ dạy phụ đạo học sinh yếu kém. Điều này giúp học sinh đạt được kết quả học tập; kết quả hạnh kiểm; kết quả đạo đức; giải quyết vấn đề trong học tập của học sinh và kết quả phân tích đã chứng minh rằng điều này có tác động tích cực đến kết quả hạnh kiểm của học sinh. Kết quả này cũng tương đồng với những nghiên cứu trước đây đã khẳng định (Shawer, 2010).

Tiếp theo kết quả phân tích hồi quy cho thấy giáo viên bộ môn (phẩm chất đạo đức, phương pháp giảng dạy, trình độ chuyên môn, năng lực sư phạm) có quan hệ tích cực đến kết quả hạnh kiểm; kết quả đạo đức của học sinh. Người thầy là tấm gương để học sinh noi theo với chuyên môn, năng lực của mình, giáo viên có thể hướng dẫn học sinh nghiên cứu khoa học, hướng dẫn học sinh học online, học sinh soạn các phiếu học tập điện tử, khai thác tài liệu trên mạng. Giáo viên là người giúp học sinh hình thành nhân cách đạo đức của người học sinh con ngoan trò giỏi, hình thành các kỹ năng sống. Điều này có tác động tích cực đến kết quả hạnh kiểm; kết quả đạo đức của học sinh. Kết quả này cũng tương đồng với những nghiên cứu trước đây đã khẳng định (Craig, 2003).

Và kết quả nghiên cứu cuối cùng là giới tính của học sinh. Theo kết quả phân tích data cho thấy tỷ lệ học sinh nữ có tác động tích cực đến khả năng tự giải quyết vấn đề trong học tập của học sinh. 


\section{Kết luận và hàm ý chính sách}

Mục đích của nghiên cứu này đã đạt được mục tiêu ban đầu đó, xác định các nhân tố ảnh hưởng đến sự hài lòng của học sinh về chất lượng giáo dục và đào tạo tại các trường THPT trên địa bàn huyện $\mathrm{Ba}$ Tri, tỉnh Bến Tre. Kết quả cho thấy giữa các yếu tố chương trình giảng dạy, giáo dục kỹ năng sống, cơ sở vật chất và cách tổ chức quản lý đào tạo của Nhà trường có tác động tích cực đến sự hài lòng của học sinh. Đặc biệt, cách tổ chức quản lý đào tạo của Nhà trường có tác động tích cực đến sự hài lòng của học sinh về chất lượng giáo dục và đào tạo của Nhà trường. Qua nghiên cứu này cũng giúp cho các nhà quản lý, quản lý tốt hơn về mục tiêu, chương trình giáo dục của Nhà trường để ngày càng nâng cao sự hài lòng của học sinh đối với cơ sở giáo dục, giúp Nhà trường tạo nên thương hiệu, uy tín để thu hút lượng học sinh có năng lực giỏi dự tuyển đầu vào.

\section{Đóng góp của đề tài về mặt học thuật}

Đây là nghiên cứu mở rộng các nghiên cứu trước đây cho bối cảnh nghiên cứu cụ thể tại 5 trường THPT ở huyện Ba Tri, tỉnh Bến Tre, Việt Nam. Nghiên cứu đã phát triển 9 biến độc lập mới (CS1, CS2, CS3, CS4, CS5, AS1, AS2, AS3, AS4) và xem xét tác động của từng biến này đối với sự hài lòng của học sinh về chất lượng giáo dục và đào tạo của Nhà trường (6 biến phụ thuộc). Kết quả làm phong phú thêm các nghiên cứu định lượng trước đây.

\section{Đóng góp đề tài về mặt thực tiễn}

Từ kết quả mở rộng các biến trong mô hình hồi quy theo hướng phát triển các biến độc lập mới phù hợp với bối cảnh nghiên cứu thực tế tại Việt Nam, kết quả phân tích hồi quy đã rút ra được nhiều hàm ý chính sách đã thảo luận chi tiết bên trên có ý nghĩa thực tế cao. Các nhà quản lý giáo dục có thể tham khảo để hoàn thiện nội dung chương trình đào tạo, các thầy cô cũng có dịp nhìn lại mình để tự hoàn thiện kỹ năng và cập nhật kiến thức đáp ứng tốt hơn sự mong đợi của xã hội.

\section{Hạn chế của nghiên cứu}

Bên cạnh những kết quả đạt, đề tài có một số hạn chế như đối tượng khảo sát là học sinh nên việc trả lời bảng khảo sát có thể cho ra một số kết quả chưa như mong muốn. Các thang đo được phát triển thông qua thảo luận nhóm có thể chưa làm đại diện tổng thể cho bối cảnh hệ thống giáo dục tại Việt Nam. Vì vậy, các nghiên cứu tiếp theo nên thực hiện thêm nghiên cứu các bên có liên quan khác như phụ huynh và các thầy cô làm phong phú thêm kết quả. Đồng thời cũng làm các bước thẩm định các thang đo mới đảm bảo tính đại diện trước khi tiến hành khảo sát.

\section{Tài liệu tham khảo}

Afework, T. H., \& Asfaw, M. B. (2014). The availability of school facilities and their effects on the quality of education in government primary schools of Harari Regional State and East Hararghe Zone, Ethiopia. Middle Eastern \& African Journal of Educational Research, 11, 59-71.

Akinsolu, R. (2004). Provision and management of facilities in Nigerian primary schools. In E. O. Fagbemiye, J. B. Babalola, M. Fabunmi, \& I. Ayeni (Eds.), Management of primary and secondary education in Nigeria. Enugu, Nigeria: NAEAP Publications. 
Anderson, R. E. (1973). Consumer dissatisfaction: The effect of disconfirmed expectancy on perceived product performance. Journal of Marketing Research, 10(1), 38-44. doi:10.1177/002224377301000106

Chingos, M. M. (2012). Citizen perceptions of government service quality: Evidence from public schools. Quarterly Journal of Political Science, 7(4), 411-445. doi:10.1561/100.00011071

Chua, C. (2004). Perception of quality in higher education. In Proceeding of the Australian Universities Quality Forum 2004 (pp. 1-7).

Craig, C. J. (2003). The relationships between and among teachers' narrative knowledge, communities of knowing, and school reform: A case of "The monkey's paw". Curriculum Inquiry, 31(3), 303-331. doi:10.1111/0362-6784.00199

Craig, C. J. (2007). Why is dissemination so difficult? The nature of teacher knowledge and the spread of curriculum reform. American Educational Research Journal, 43(2), 257-293. doi:10.3102/00028312043002257

Giese, J. L., \& Cote, J. A. (2000). Defining consumer satisfaction. Academy of Marketing Science Review, 1(1), 1-22.

Kelly, J. M. (2002). If you only knew how well we are performing, you'd be highly satisfied with the quality of our service. National Civic Review, 91(3), 283-292. doi:10.1002/ncr.91307

Knight, P., Tait, J., \& Yorke, M. (2006). The professional learning of teachers in higher education. Studies in Higher Education, 31(3), 319-339. doi:10.1080/03075070600680786

Kotler, P., \& Armstrong, G. (2008). Establishing the mission. In Principles of marketing (pp. 131-133).

Latham, N. I., \& Vogt, W. P. (2007). Do professional development schools reduce teacher attrition?: Evidence from a longitudinal study of 1,000 graduates. Journal of Teacher Education, 58(2), 153-167. doi:10.1177/0022487106297840

Lee, O., Maerten-Rivera, J., Penfield, R. D., Leroy, K., \& Secada, W. G. (2008). Science achievement of English language learners in Urban elementary schools: Results of a firstyear professional development intervention. Journal of Research in Science Teaching, 31(1), 69-82. doi:10.1002/tea.20209

Morgeson, F. V. (2013). Expectations, disconfirmation, and citizen satisfaction with the US federal government: Testing and expanding the model. Journal of Public Administration Research and Theory, 23(2), 289-305. doi:10.1093/jopart/mus012

Newton, K., \& Norris, P. (2019). Three. Confidence in public institutions: Faith, culture, or performance? In Disaffected democracies (pp. 52-73). doi:10.1515/9780691186849-007

Oliver, R. L. (1980). A cognitive model of the antecedents and consequences of satisfaction decisions. Journal of Marketing Research, 17(4), 460-469.

Parasuraman, A., Berry, L. L., \& Zeithaml, V. A. (1993). More on improving service quality measurement. Journal of Retailing, 69(1), 140-147. doi:10.1016/S0022-4359(05)800077 
Randolph, D., Duffy, E., \& Mattingly, K. (2007). The 3 P's of curriculum redesign: Principles, personal qualities and process. Independent School, 66(3), 86-92.

Riccucci, N. M., Van Ryzin, G. G., \& Lavena, C. F. (2014). Representative bureaucracy in policing: Does it increase perceived legitimacy? Journal of Public Administration Research and Theory, 24(3), 537-551. doi:10.1093/jopart/muu006

Roch, C. H., \& Poister, T. H. (2006). Citizens, accountability, and service satisfaction: The influence of expectations. Urban Affairs Review, 41(3), 292-308. doi:10.1177/1078087405281124

Roehrig, G. H., Kruse, R. A., \& Kern, A. (2007). Teacher and school characteristics and their influence on curriculum implementation. Journal of Research in Science Teaching, 44(7), 883-907. doi:10.1002/tea.20180

Shawer, S. F. (2010). Classroom-level teacher professional development and satisfaction: Teachers learn in the context of classroom-level curriculum development. Professional Development in Education, 36(4), 597-620. doi:10.1080/19415257.2010.489802

Shawer, S. F. (2017). Teacher-driven curriculum development at the classroom level: Implications for curriculum, pedagogy and teacher training. Teaching and Teacher Education, 63(April), 296-313. doi:10.1016/j.tate.2016.12.017

Shawer, S. F., Gilmore, D., \& Banks-Joseph, S. R. (2008). Student cognitive and affective development in the context of classroom-level curriculum development. Journal of the Scholarship of Teaching and Learning, 8(1), 1-8.

Shawer, S. F., Gilmore, D., \& Banks-Joseph, S. R. (2009). Learner-driven EFL curriculum development at the classroom level. International Journal of Teaching and Learning in Higher Education, V20 N2, 20(2), 125-143.

Snyder, J., Bolin, F., \& Zumwalt, K. (1992). Curriculum implementation. In P. W. Jackson (Ed.), Handbook of research on curriculum (pp. 402-435). New York, NY: Macmillan.

Song, M., \& Meier, K. J. (2018). Citizen satisfaction and the kaleidoscope of government performance: How multiple stakeholders see government performance. Journal of Public Administration Research and Theory, 28(4), 489-505. doi:10.1093/jopart/muy006

Van Ryzin, G. G., Muzzio, D., Immerwahr, S., Gulick, L., \& Martinez, E. (2004). Drivers and consequences of citizen satisfaction: An application of the American customer satisfaction index model to New York City. Public Administration Review, 64(3). doi:10.1111/j.1540-6210.2004.00377.x 